\title{
Tierischer als jeder Tier': \\ as assembleias gerais digitais ou semipresenciais em cooperativas como controladoras de dados dos seus cooperados
}

Tierischer als jeder Tier: digital or semi-general general meetings in cooperatives as data controllers of their members

\author{
Guilherme Krueger ${ }^{2}$ \\ CPJM-Universidade Estadual do Rio de Janeiro
}

Tatiana Gonçalves Moreira

Associação dos Profissionais de Proteção e Segurança de Dados de Portugal ${ }^{3}$

Sumário: 1. À guisa de introdução: Democracia, cooperativa e modernidade relacionadas a partir uma estória contada por Goethe. 2. As assembleias gerais de cooperativas em ambiente digital: o novo normal. 3. A proteção de dados pessoais sob a perspectiva das Assembleias Gerais digitais ou semipresenciais. 4 À guisa de conclusão: o paradoxo da liberdade coercitiva. 5. Apêndice. Referências bibliográficas.

Resumo: Com propedêutica referenciada na personagem Fausto, de Goethe, uma correlação fenomenológica entre a gestão democrática das cooperativas e tecnologia da informação é feita com a abordagem das Leis brasileiras 13.709/18 e 14.030/20, respectivamente a Lei Geral de Proteção de Dados (LGPD) e alteração na Lei Geral das Cooperativas (Lei 5.764/71) para previsão das assembleias gerais digitais ou semipresenciais. A correlação expõe uma instabilidade potencial entre a supremacia democrática manifesta em suas assembleias e o desempenho tecnológico marcado por densa normatividade regulatória.

Palavras-chave: Democracia - tecnologia da informação - cooperativas proteção de dados.

1 Mais feroz que toda fera: confira os versos de Goethe na epígrafe do texto.

2 Centro de Pesquisa em Crimes Empresarias e Compliance. Departamento de Direto Penal da Faculdade de Direito da UERJ. E-mail: guilherme@gomeskrueger.adv.br

3 Associação dos Profissionais de Proteção e Segurança de Dados de Portugal. E-mail: tatiana@ffmoreiraadv.com.br 
Abstract: With a propaedeutic referenced in the character Fausto, by Goethe, a phenomenological correlation between the democratic management of cooperatives and information technology is made with the approach of Brazilian Laws 13.709 / 18 and 14.030 / 20, respectively the General Data Protection Law (LGPD) and amendment to the General Law of Cooperatives (Law $5.764 / 71$ ) to provide for digital or semi-presential general assemblies. The correlation exposes a potential instability between the democratic supremacy manifested in its assemblies and the technological performance marked by dense regulatory normativity.

Keywords: Democracy - information technology - cooperatives - data protection. 
Er nennt's Vernunft und braucht-s allein,

Nur tierischer als jeder Tier zu sein ${ }^{4}$

Mefistofeles

\section{1. À guisa de introdução: Democracia, cooperativa e modernidade relacionadas a partir uma estória contada por Goethe}

Poucos anos antes do advento das cooperativas em Alemanha, Goethe deu feição a uma representação icônica dos seus cooperados: Fausto. A personagem é concebida a partir da memória de um vilão, Johann Georg Faust, cuja biografia restava envolta em lenda desde o crepúsculo da época medieval. Na lenda, se manifesta uma audácia de saber que advém do abandono de uma atitude contemplativa de Deus pela autonomia em contratar com o Diabo. Esta personagem, antes de chegar à obra de Goethe, se insinuou no imaginário moderno, quando em 1587 houve a impressão de Johann Spies: Historia von Dr. Johann Fausten, também conhecido como Faustbuch; primeiro registro substancial da lenda e referência para a primeira obra dramatúrgica protagonizada pelo personagem, The Tragical History of Doctor Faustus, de Christopher Marlowe, publicada no início do sec. XVII.

A reviravolta dada por Goethe ao desfecho trágico das narrativas anteriores na segunda peça que escreveu para o protagonista será marcante pela prevalência da autonomia desejante numa destinação criativa sobre o destino sempre dado desde a criação heteronômica, a causa sui. No Fausto finalmente refigurado por Goethe em 1832, o herói completa em sua personalidade e peripécia voltadas para o desfecho inventivo uma relação paradigmática entre vontade e inteligência humanas que vinha se tornando típica do ideário moderno. Porém, permanece no Fausto de Goethe a terrível ferocidade suprema do desejo humano por si mesmo, o que ele coloca na boca do demônio tal como transcrito na epígrafe deste artigo.

Inventividade e desejo; vontade e sagacidade. As vicissitudes nas múltiplas possibilidades do enredamento narrativo com o dispositivo desses pares duplicados como locanda do enredo (seu enquadramento sem qualquer fixação espaço-temporal de cena) já eram notáveis nos antigos mitos gregos. Em particular, dois personagens míticos carregam este enquadramento nas suas narrativas: Prometeu e Sísifo. É ver-

4 Dá-lhe o nome de razão e a usa afinal/apenas para ser mais feroz que toda fera. 
dade que os gregos clássicos desconheciam a ideia de salvação. Daí que as vicissitudes restem insuperáveis, o que é compatível com a estrutura necessariamente circular do tempo em todo mito. Mas, a acuidade dos gregos nesse enquadramento das vicissitudes será determinante para a origem da democracia entre eles.

Essa determinação é perceptível só por uma visada transversal da cultura ateniense na época em que na cidade foi instituída a democracia. Porque será necessário considerar que a origem da democracia seja indissociável de outra realização clássica dos gregos: a dramaturgia trágica. Também é verdade que eles desconheciam a ideia de humanidade. Daí que seja tão importante o deslizamento da narrativa mítica para a narrativa dramatúrgica, pois foi com as tragédias que os gregos encontraram expressividade para colocar os homens como preocupação em pensamento, o que dá conta da característica primária da democracia: os homens decidem entre si e estão ciosos disso. Sintomático na Oresteia de Ésquilo, Palas Athena proferiu seu voto de Minerva se dirigindo às Fúrias no contexto de uma assembleia deliberativa de homens que estava presa a um impasse. E Sófocles irá conformar a preocupação de Ésquilo numa investigação nomológica, o que é patente no diálogo entre Antígona e Creonte ao fim das vicissitudes dramatúrgicas enfrentadas pelos descendentes de Lábdaco e por essa linhagem ligados à fundação mítica da cidade de Tebas. É sugestivo notar que a investigação nomológica já insinue também uma estrutura linear de tempo na trajetória dos descendentes; linha esta que vai escapando de um mito genético.

Para o que interessa a este artigo: a investigação nomológica de Sófocles em Antígona e Creonte indicia a sua preocupação com a normatividade na democracia e se volta para a importância da dramaturgia trágica na contenção da ferocidade do desejo humano entre os gregos reunidos em assembleia. A suspeita de que com a rigidez em sua formulação e sendo encenada repetidamente, a dramaturgia trágica perdia o seu efeito catártico e que a democracia fosse afinal incapaz de lidar com os desejos tomou uma expressão contundente no suicídio de Sócrates narrado por Platão e foi expresso exaustivamente no diálogo com Protágoras: se a ferocidade for polida, os desejos humanos tomam a forma de argumentos tão engenhosos como ardilosos. Essa questão foi finalmente posta a nu por Nietzsche em sua Genealogia da Moral, na qual a vontade de poder vai se travestindo na vontade de verdade, cuja relação entre elas é encoberta pelo elogio à audácia de saber.

A obra de Platão foi decisiva para que a democracia fosse sendo preterida como arranjo político conveniente até que houvesse a sua 
revalorização na modernidade com o surgimento do humanismo. Mas, mesmo nesta época, o Leviatã de Hobbes constitui resposta eloquente ao convívio humano, conquanto seus desejos sejam potencialmente indutores ao estado de guerra. A seu turno, Tocqueville observou como os migrantes nos nascentes Estados Unidos da América eram seduzidos pelo aparato democrático quanto ao seu desejo incessante de ascensão social e assim induzidos pela ambição a perscrutar objetivos incessantemente propostos - aquilo que comumente aludimos por sonhos:

[A igualdade material] escapa todos os dias das mãos do povo no momento em que ele pensa agarrá-la, e foge, como diz Pascal, uma fuga eterna; o povo se inflama em busca desse bem tanto mais precioso por estar perto o bastante para ser conhecido, longe o bastante para não ser provado. A possibilidade de ter êxito comove-o, a incerteza do sucesso irrita-o; ele se agita, se cansa, se azeda. Tudo o que o supera por algum viés parece-lhe então um obstáculo a seus desejos, e não há superioridade tão legítima cuja visão não canse seus olhos. ${ }^{5}$

A resiliência demonstrada pela democracia moderna, no entanto, apresenta algo que já vai insinuado no próprio texto de Tocqueville: o consumo canaliza os desejos humanos. A intensificação das relações tecidas entre sociedade de mercado e o Estado Democrático de Direito são em grande medida responsáveis por esta resiliência. Neste ponto, se situa o cooperativismo como organização comunitária economicamente organizada com gestão democrática, conquanto seu fim esteja voltado à satisfação de seus cooperados. As cooperativas associam diretamente democracia de sua gestão a um perfil consumerístico de tratamento social a ser dado aos cooperados, o que comumente vem expresso também como acréscimo de renda ou incremento à sua produtividade. Seja pelo viés do consumo, da renda ou da produção, trata-se sempre de consumação.

Ocorre que a consumerística (as relações entre consumo, consumação e consumição) carrega necessariamente em si um caráter estético: o significado de bem estar presente na experiência emotiva e sensorial pelo ato finalístico em toda cooperativa. E este caráter responde pelo efeito transitório dessa satisfação. Portanto, essencial-

5 Tocqueville reconheceu os perigos permanentes da democracia moderna: a frustração dos desejos insaciáveis, agitação psicológica e preocupações penosas. Alex de Tocqueville. A Democracia na América. Leis e Costumes. Trad. Eduardo Brandão. 2. ${ }^{a}$ Ed. (São Paulo: Martins Fontes, 2005), 231-232. 
mente instável ${ }^{6}$. Os desejos continuam sempre a pressionar a gestão democrática por resultados mais imediatos. Por esta dinâmica entre desejos e instabilidades emocionais se pode perscrutar o acontecimento de uma assembleia de cooperados reunidos na cooperativa desde a ágora grega, que é tanto lugar das transações de mercado e de deliberação democrática. E também de encenação da dramaturgia trágica. Esse traço é perceptível na forma similar em que se dispõe a mesa de condução de uma assembleia de cooperativa face aos olhares dos cooperados e a boca de cena em que atores se apresentam no teatro. Tanto os dirigentes de cooperativa como os atores de teatro tecem uma narrativa em que o plenário dele participa nem tão próximo que se confundam com o próprio acontecimento, nem tão distante que lhes seja indiferente.

Neste ponto, passo então a abordar a Lei 14.030/2020.

6 Assistimos nessa interessante aliança entre as indústrias da experienciação e movimentos identitários de gêneros e raças um esforço comum na dissolução de toda heteronomia, que se torna confusa como humilhação. Essa dissolução concebe qualquer um simplesmente alguém vazio (não-ser) que se preenche do vir a ser simesmo expresso como empoderamento. Toma-se por epígrafe disso a famosa máxima de Simone de Beauvoir: ninguém nasce mulher, torna-se mulher. E como se positiva esse preenchimento? No desempenho em ser o que quiser ser. Um sujeito de desempenho. E o desempenho se torna um excesso de positividade: Yes, we can; me too.

"A lamúria do indivíduo depressivo de que nada é possivel só se torna possível numa sociedade que crê que nada é impossível. (....) O sujeito de desempenho encontra-se em guerra consigo mesmo. O depressivo é o inválido dessa guerra internalizada. A depressão é o adoecimento de uma sociedade que sofre sob o excesso de positividade. Reflete aquela humanidade que está em guerra consigo mesma.

O sujeito de desempenho está livre da instância externa de domínio que o obriga a trabalhar ou que poderia explorá-lo. É senhor e soberano de si mesmo. Assim, não está submisso a ninguém ou está submisso apenas a si mesmo. É nisso que ele se distingue do sujeito de obediência. A queda da instância dominadora não leva à liberdade. Ao contrário, faz com que liberdade e coação coincidam. Assim, o sujeito de desempenho se entrega à liberdade coercitiva ou à livre coerção de maximizar o desempenho. (....) Os adoecimentos psíquicos da sociedade de desempenho são precisamente as manifestações patológicas dessa liberdade paradoxal.»

Byung-Chul Han. Sociedade do Cansaço. Trad. Enio Paulo Giachini. (Petrópolis: Vozes, 2015.), 29-30. 


\section{As assembleias gerais de cooperativas em ambiente digital: o novo normal}

Embora não houvesse uma proibição expressa, o recurso tecnológico para realização de assembleias por video, chats, audios e votação era uma alternativa nada usual. Não havia segurança de que as suas atas fossem registradas em cartório. A Lei geral das cooperativas é datada de 1971, quando essa possibilidade tecnológica não passava de uma fantasia de ficção científica.

As descrições notadamente especificadas das exigências de publicidade do edital no art. $38, \S 1 .^{\circ}$ se constituem na primeira dificuldade prática aos custos de transação para assembleias gerais em ambiente digital. Esta dificuldade se situa na publicação em jornal. A orientação dada até hoje pelo Departamento Nacional de Registro Empresarial e Integração (DREI) se refere a esta exigência como título com circulação regular e geral com folha identificada do jornal e determinação precisa da data de sua publicação. Como se percebe, a referência paradigmática continua sendo somente o veículo impresso em papel. A desconsideração do jornal on line pela regulação cartorial é uma importante defasagem para a migração das assembleias para o ambiente digital.

As edições on line já se tornaram incontornáveis para os veículos jornalísticos. No início, as versões digitais eram uma reprodução do material impresso. Mas já ganharam tantas funcionalidades de interação que se tornaram autônomas ao material impresso. A mais notável característica própria da edição on line é a significativa participação ativa dos leitores na produção jornalística. As funcionalidades mais comuns de interação são os comentários, os compartilhamentos em redes sociais, as curtidas nos posts, a assinatura de newsletters e a aferição em posicionamento nos sites de buscas.

Parece indiscutível que a veiculação on line têm potencial para a saturação democrática da gestão das cooperativas com a ampliação do engajamento dos cooperados, porque revelam mais dados sobre o modo como os cooperados se envolvem, positiva ou negativamente com a cooperativa. O acompanhamento desse engajamento e a sua responsividade contribuem para que os gestores da cooperativa possam melhor definir (1) os conteúdos de pauta para além das exigências legais predefinidas e a propagação dos temas entre os cooperados, (2) a coleta e tratamento das opiniões dos cooperados com maior compreensão e devolução entre conjunto do quadro societário e a pessoa de cada cooperado, (3) o formato das deliberações.

A tecnologia, como este nome indica, é a lógica da técnica dobrada sobre si mesma. Sendo maquinação, diz tanto dos cooperados 
quanto diga de uma unidade um número infinito de noves à direita de uma vírgula posta logo após do dígito zero. O cooperado sendo locanda (situação móbil) fenomênica em relações constitutivas de uma comunidade democrática e economicamente organizada, não pode ser totalizado por cálculos sequenciais. Pois, tecnologia não produz conhecimento e muito menos sabedoria. A tecnologia produz dados sistemática e processualmente tratados. A cooperativa precisa agregar conhecimento a estes dados, sistemas, processos e tratamentos pelos saberes modulados da psicologia e antropologia que podem propor crenças verdadeiramente justificadas com rigor acerca dos cooperados naquilo que deles esses dados podem informar. É com essa perspectiva que a cooperativa, ao realizar seus conclaves em ambiente digital precisa reencontrar a ágora grega.

A cooperativa é tratada pelo Código Civil brasileiro como uma sociedade simples (não empresária) por ser uma união de pessoas organizadas com finalidade econômica, mas essa finalidade será outra que não o lucro. A sua finalidade é definida pelo art. $7 .^{\circ}$ da Lei 5.764/71: a prestação de serviços aos seus cooperados. No mesmo sentido de Gemeinnutzvorrang atribuído pelos alemães ou scopo mutualístico, pelos italianos ou como os franceses a define: de manière à satisfaire les besoins économiques ou sociaux par leur effort commun. As cooperativas são concebidas no Brasil para a economia de escala, visto o número mínimo obrigatório de 20 pessoas físicas como sócias? (salvo as cooperativas de trabalho ${ }^{8}$ ) e, sobretudo, na medida em que não lhes seja facultada a opção do regime tributário compatível com micro e pequenas empresas ${ }^{9}$.

Em que pese singularidade do escopo mutualístico nas cooperativas em relação às sociedades empresárias em geral, é preciso compreender, mesmo assim, a cooperativa como empresa, se esta for, por sua vez, compreendida como um relevante centro de imputação jurídica face terceiros em termos de estabilidade socioeconômica, inclusive no que se refere aos direitos individuais homogêneos e coletivos ou interesses difusos sob o impacto das atividades delas com seus respectivos cooperados. Existem muitos direitos e interesses de terceiros a serem considerados: desde credores até consumidores, além de aspectos múltiplos da proteção ambiental e concorrencial, quando se considera a escala econômica que uma cooperativa bem sucedida pode alcançar. Por isso, razoável o registro de seus atos deliberativos supremos em

\footnotetext{
7 Art. $6 .^{\circ}$, I da Lei $5.764 / 71$.

8 Art. $6^{\circ}$ da Lei $12.690 / 2012$.

9 Art. $3^{\circ}, \S 4 .^{\circ}, \mathrm{VI}$ (exceto as de consumo).
} 
cartório voltado às sociedades empresárias (as juntas comerciais), e não os cartórios de registro de pessoas jurídicas, como as associações.

A funcionalidade do registro em junta comercial pressupõe maior rigor formal, consoante normas expedidas pela União Federal através da DREI. Justifica-se a ampla publicidade legalmente exigível aos seus editais de convocação de assembleias gerais. Resta, no entanto em questão, se ainda seja funcional a publicação em edição impressa de jornal, se consideramos as alternativas digitais que potencialmente melhor cumpram o objetivo de publicidade. A diminuição expressiva de leitores das edições impressas ante a possibilidade de se acessar informações jornalísticas pela via digital é uma variável determinante para a avaliação desta funcionalidade. Haveria alguma alternativa à publicação em edição jornalística impressa, mas com melhor performance? Provavelmente, sim.

Há hoje táticas de publicidade digital de eficácia comprovadas. O aproveitamento da internet (suas plataformas, tecnologias, canais e recursos) logra efetiva exposição de dados formatados em texto de gêneros descritivo e injuntivo (característicos de edital) ao público, que pode ser inclusive segmentado eficientemente em destinatários alvo ${ }^{10}$. Já existem alguns precedentes legislativos que refletem essa tendência de melhor aproveitamento do ambiente digital para a publicidade legalmente exigível. $O$ art. $4 .{ }^{\circ}, \mathrm{I}$, da Lei $n .^{\circ}$ 10.520/02 faculta a publicidade legalmente exigível pelo meio eletrônico ao tratar do Direito Administrativo. $O$ art. 17 do Decreto n. ${ }^{\circ}$ 5.450/05 então modulou necessidade de publicar aviso de pregão eletrônico em jornal de grande circulação. A seu turno, o Superior Tribunal de Justiça modulou a exigibilidade de publicação em jornal na aplicação do art. 144 da Lei 11.101/05, pois afastou a cominação do $\S 1 .^{\circ}$ do art. 142 para fins de alienação extraordinária de ativos de uma massa falida em decisão do Recurso Especial 1.356.809, em julgamento realizado pela sua 3. ${ }^{a}$ Turma (Direito Privado) em 10/02/2015, acórdão publicado em Diário Oficial 18/02/2015, mas disponível em meio digital desde o dia 13/02. Em

10 Aliás, a publicidade digital tem efetividade tal que acaba por ilustrar bem o paradoxo pós-moderno: quanto mais se comunica, menos se entende. De certo modo, com a descoberta de uma linguagem transparente, porque restrita às variações sequenciais de possibilidades binárias, se pretendeu erigir um acesso universal ao entendimento. Só para nos descobrirmos fascinados por uma nova torre de Babel, quando nos surpreendemos encerrados em bolhas de significações compartilhadas de modo cada vez mais restrito e impermeável; bolhas estas que são emergentes de uma fragmentação acelerada de imaginários históricos-sociais pela (cada vez mais direcionada) adição sistemática e exponencial, pela via digital, de dados linguísticos que suportam qualquer significação performática num estímulo à imaginação. 
todo caso, no que se refere ao tema deste artigo, debalde indícios de que a publicação em jornal com circulação impressa esteja deixando de ter a relevância de outrora para fins legais, a Instrução Normativa DREI $81 / 2020$, em seu anexo VI (manual para registro dos atos praticados por cooperativas em Juntas Comerciais), item 1.4, mantém a exigência de publicação de edital de assembleia em jornal impresso sem qualquer modulação por faculdade de manejo da publicidade digital.

Mas, por outro lado, a IN DREI 81/2020, em seu anexo VI, é inovadora ao incorporar uma seção dedicada às reuniões ou assembleias semipresenciais ou digitais. E o faz por força da Lei 13.040/2020 que introduziu na Lei 5.764/71 o seguinte dispositivo:

Art. 43-A. O associado poderá participar e votar a distância em reunião ou em assembleia, que poderão ser realizadas em meio digital, nos termos do regulamento do órgão competente do Poder Executivo federal.

Parágrafo único. A assembleia geral poderá ser realizada de forma digital, respeitados os direitos legalmente previstos de participação e de manifestação dos associados e os demais requisitos regulamentares.

Essa alteração legislativa incorpora explicitamente o ambiente digital às cooperativas e, mais, produz um reencaixe espaço-temporal para a gestão democrática das cooperativas. A seção III do anexo VI da IN DREI 81/2020 está transcrita em apêndice a este artigo.

A novidade legislativa traz implicações hermenêuticas para a Lei 5.764/71. O seu art. $4 .^{\circ}$, XI caracteriza uma cooperativa como tendo uma área de admissão de associados limitada às possibilidades de reunião, controle, operações e prestação de serviços ${ }^{11}$. Ao menos quanto à reunião, a participação remota de cooperados em ambiente digital, ou seja, sem a necessidade de deslocamento físico hábil para a sua participação em tempo real torna as possibilidades mais plásticas e, com isso, factíveis novas conformações constitutivas da sociedade que antes não eram viáveis. É o caso das cooperativas de plataforma.

O art.42, § $2^{\circ}$ da Lei 5.764/71 permite que cooperativas com mais de 3.000 (três mil) que os cooperados sejam representados nas Assembleias Gerais por delegados que tenham a qualidade de associados no gozo de seus direitos sociais e não exerçam cargos eletivos na sociedade. As assembleias em ambiente digital tornam possível um reen-

11 O mesmo está previsto no art. $10, \S 3 .^{\circ}$ da Lei 12.690/2020 com relação às cooperativas de trabalho. 
caixe da democracia direta na ampliação da escala numa cooperativa. Cooperativas de crédito, consumo e infraestrutura tendem a ter um quadro massivo de cooperados e já podem prescindir dos grupos seccionais e delegados para viabilizar a reunião em assembleia num espaço físico único. O mesmo se diga do $\S 4 .^{012}$, quanto a cooperativas agropecuárias ou de transporte de carga e de passageiros por aplicativo que podem estender sua área de ação e de admissão de cooperados sem que haja inibições quanto à capacidade real de reunião de seus cooperados que só poderiam ser resolvidas pela delegação. Abre-se um horizonte de organização cooperativa em larga escala para o desenvolvimento local no qual os nexos espaço-temporais são recontextualizados em desencaixes e reencaixes possíveis nos ambientes digitais.

Em todo caso, como o desencaixe e reencaixe são possíveis? Desde o relógio (cronometria) e o mapa-múndi (cartografia), todo desencaixe e reencaixe espaço-temporal só pode ser realizado por meio de um sistema perito. A IN DREI 81/2020 se refere a um «sistema [eletrônico] e tecnologia acessíveis [via rede mundial de computadores] para que todos os associados participem e votem a distância na assembleia». E admite a necessidade de peritos, pois «a sociedade pode contratar terceiros para administrar, em seu nome, o processamento das informações nas reuniões ou assembleias semipresenciais e digitais», enquanto permanece responsável pelas condições adequadas de desencaixe e reencaixe espaço-temporal na gestão democrática da cooperativa. A perícia é polarizada (em sentido axiológico) pela segurança, a confiabilidade e a transparência exigíveis ao sistema e tecnologia adotadas face aos cooperados, ora usuários. O que remete a gestão democrática das cooperativas à Lei Geral de Processamento de Dados (LGPD).

\section{A proteção de dados pessoais sob a perspectiva das Assembleias Gerais digitais ou semipresenciais}

A Lei Geral de Proteção de Dados ${ }^{13}$ foi sancionada no Brasil em agosto de 2018 em consonância com o movimento mundial de busca pela garantia da privacidade e proteção de dados pessoais do titular, comumente utilizados de forma indevida e arbitrária. Até a criação da

$12 \S 4 .^{\circ}$ Admitir-se-á, também, a delegação definida no parágrafo anterior nas cooperativas singulares cujo número de associados seja inferior a 3.000 (três mil), desde que haja filiados residindo a mais de $50 \mathrm{~km}$ (cinquenta quilômetros) da sede.

13 Lei 13.709/18. 
LGPD, o Brasil contava com leis setoriais que formavam uma «colcha de retalhos», sem qualquer uniformização de seu regramento.

De acordo com Bruno Bioni14, esses gaps ou lacunas no ordenamento jurídico brasileiro, geravam insegurança jurídica tanto para o titular, uma vez que não detinha de uma proteção satisfatória, clara e transparente em suas atividades cotidianas, nas situações em que fornecia seus dados pessoais, como para as parcerias público-privadas e para as políticas públicas e de desenvolvimento de setores produtivos.

Quando abordada a temática da proteção de dados, a insegurança ou segurança (a depender do ângulo que se deseja analisar) não se limita aos aspectos jurídicos, porque a tecnologia compõe o cenário de volatilidade, incerteza, complexidade e ambiguidade que marca a contemporaneidade. Com a evolução da tecnologia, o que por um lado criou facilidades e acessos, de outro criou um ambiente hostil, onde dados são comercializados a todo instante como ativo de grande valia. De encontro a práticas tão danosas quanto banalizadas, foi necessário reafirmar fundamentos civilizatórios como a confidencialidade, integridade, disponibilidade e autenticidade para garantir a proteção dos dados das ameaças internas e externas.

Recentemente, o mundo se deparou com uma situação inusitada de isolamento. A quebra de paradigmas diante da realidade do isolamento, fez com que muitas organizações, instituições e empresas em geral se vissem compelidas a adequarem seus modelos de negócio, agora muito mais dependentes do ambiente virtual. Ferramentas tecnológicas antes utilizadas só por alguns, passaram a fazer parte do cotidiano de muitos e a transferência de dados, em especial dos pessoais, passou a ser ainda mais intenso e rotineiros.

Essa nova demanda impôs desafios, adequações e demandas por investimentos à sociedade como um todo, tanto sob a perspectiva humana quanto tecnológica. O uso massivo da internet e a necessidade de continuidade da sociedade como organismo vivo, exigiu grande reflexão e intensa criatividade na busca de soluções. Em que pese haver um desconforto na mudança do modus operandi de diversas situações, estas também impulsionaram o desenvolvimento e a modernização de processos arcaicos e pouco efetivos.

A Assembleia Geral prevista na década de 70, diante do novo normal, se deparou com uma realidade limitadora e incapacitante, quando da ausência de previsão nos atos constitutivos da cooperativa para sua

14 Bruno Ricardo Bioni. Proteção de dados pessoais: a função e os limites do consentimento. 2. ${ }^{a}$ Reimpr. (Rio de Janeiro: Forense, 2019.) 108-109. 
realização na modalidade virtual. Apesar de não haver proibição expressa na lei, a modalidade virtual era, até então, pouco utilizada e, portanto, não prevista na maior parte dos atos constitutivos.

Quando do novo cenário, a utilização de recurso tecnológico na Assembleia Geral deixou de ser uma mera opção e passou uma boa prática na garantia do exercício do direito de voto e cumprimento das demais obrigações dentro de prazos legais. Esse impulso não planejado das Assembleias Gerais ao ambiente virtual abre espaço para a reflexão quanto às exigências atuais de publicidade, ora já mencionadas, como também para a necessidade de adequação às necessidades sociais atuais.

Essa dinâmica de desencaixe e reencaixe da democracia no ambiente das cooperativas suscita também a pertinência quanto a segurança, privacidade, proteção dos dados pessoais e o uso da internet para o exercício regular dos direitos dos cooperados. Nesta toada, a Lei 12.965/2014 ${ }^{15}$, conhecida como o Marco Civil da Internet reconhece ser devido ao usuário informações claras e completas sobre coleta, uso, armazenamento, tratamento e proteção de seus dados pessoais, que somente poderão ser utilizados para finalidades que a respeito de seu tratamento, tenham uma justificativa para a coleta, não tenham impedimento legal e sejam de conhecimento e acesso inequívoco nos contratos de prestação de serviço ou nos termos de uso de aplicação da internet ${ }^{16}$.

Com as vicissitudes advindas da Era da Informação, a simples disponibilidade de recursos tecnológicos apresenta-se como solução insuficiente para assegurar o exercício da cidadania e dos direitos e garantias fundamentais previstos na Carta Magna Brasileira de 198817. Isso porque, com as novas demandas e recursos, o volume de fluxo de dados ganha enorme proporção, sendo necessário especificar como o tratamento de dados pessoais será operacionalizado de modo a observar e preservar a liberdade e a privacidade de seus titulares. Neste contexto globalizado, surge a Lei Geral de Proteção de Dados, a LGPD, com o desafio de assegurar, por parte dos agentes de tratamento de dados pessoais, seja ele o controlador ou o operador, a segurança aos titulares quanto ao tratamento a ser designado aos seus dados pessoais. E, no contexto das assembleias digitais das cooperativas, isso não é diferente.

15 Lei 12.965, de 23 de abril de 2014. Estabelece princípios, garantias, direitos e deveres para o uso da Internet no Brasil.

16 Lei $12.965 / 2014$, Art. $7 .^{\circ}$, inciso VIII e alíneas.

17 Art. 5 da CF/88. 
As cooperativas como controladoras ${ }^{18}$ que são, uma vez que competem a essas as decisões relativas ao tratamento de dados pessoais de seus cooperados e associados, passam a ter um papel ainda mais relevante na governança dos dados pessoais, bem como na propagação das boas-práticas.

De maneira objetiva, os princípios elencados no art. 6. ${ }^{\circ}$ da LGPD ${ }^{19}$ devem ser incorporados nas rotinas das Cooperativas, informando ao cooperado de forma clara, explícita e específica, qual é a finalidade e o propósito legítimo para a realização do tratamento dos dados pessoais solicitados por ela.

A precisa identificação dos dados necessários para a realização da finalidade pré-estabelecida exige quebra de paradigma e mudança na cultura dos controladores, quanto aos dados realmente indispensáveis para o exercício da finalidade proposta. A abrangência e proporcionalidade devem coadunar com a finalidade em si, deixando à margem da coleta os dados dispensáveis para este fim. O dito popular de que "menos é mais» se aplica perfeitamente à lógica da LGPD, devendo, portanto, serem coletados tão somente os dados essenciais à plena execução da ação.

Qualquer alteração na finalidade, deve o titular do dado ser comunicado de imediato para garantir a transparência e conceder novo consentimento, caso não seja hipótese de cumprimento de obrigação legal, execução de contrato, proteção à vida, legítimo interesse do controlador ou outra prevista no art. $7 .^{\circ}$ da LGPD.

O acesso do cooperado aos seus dados pessoais é imperioso para que se lhe garanta a constatação por si mesmo da integridade dos dados, bem como a sua exatidão, relevância e clareza, quanto à forma e duração do tratamento em questão. Sob a perspectiva da proteção de dados, em consonância com o livre acesso do titular, a confidencialidade é o que garante que os dados estejam acessíveis apenas às pessoas autorizadas, assegurando o sigilo destes a terceiros.

Quanto à Assembleia digital ou semipresencial, haja vista que este produzirá os mesmos efeitos legais de uma presencial, caberá aos administradores assegurar a identificação do voto aberto e a segurança no sigilo do voto fechado. A autenticação é a principal forma de garantir esse controle de validação e a restrição do acesso indevido aos dados pessoais armazenados. Através de log de acesso individualizado, será possível identificar o usuário que declarou o voto ou manipulou aquele dado e conferir sua autenticidade, sendo certo que esta ação

18 Art. 5, VI, da Lei 13.709/18.

19 Art. $6^{\circ}$ da Lei 13.709/18.

Deusto Estudios Cooperativos 
gerará um documento, um registro. Esse documento é de grande importância, pois, juntamente com outros processos de gestão de dados, diante de um questionamento, seja ele do titular ou de algum órgão governamental, a prova de adoção de técnicas de segurança e de boas práticas estarão ali identificadas.

Apesar da responsabilidade atribuída na Política Nacional de Cooperativismo 20 aos administradores, com o advento da LGPD surge uma nova figura neste cenário, a do Encarregado, que, na Europa ficou conhecido como DPO (Data Protection Officer). A função de DPO, advinda do Regulamento Europeu de Proteção de Dados (General Data Protection Regulation-GDPR), a despeito de ser comumente usada no Brasil como sinônimo do Encarregado, não tem o mesmo significado malgrado de suas similitudes.

O Encarregado, de acordo com o art. 5. ${ }^{\circ}$, inciso VIII, da LGPD, é «pessoa indicada pelo controlador e operador para atuar como canal de comunicação entre o controlador, os titulares dos dados e a Autoridade Nacional de Proteção de Dados (ANPD)», ou seja, é a pessoa que responsável pela conexão e observação das exigências legais, em especial ao cumprimento dos direitos individuais dos titulares.

A nomeação do Encarregado, por sua vez, é obrigatória para quem realiza tratamento de dados pessoais e representa uma posição estratégica dentro da organização. No caso das cooperativas, o Encarregado deve exercer seu cargo lado a lado com o controlador que, deverá passar todas as informações que identifiquem atividade de tratamento de dados. O entendimento do ciclo de vida dos dados pessoais pelo Encarregado será de suma importância para que o tratamento esteja em conformidade aos princípios, direitos e demais normas.

O Encarregado além de ser o ponto de contato entre a cooperativa, os titulares e a Autoridade Nacional de Proteção de Dados (ANPD) e ainda ser conhecedor do ciclo de vida dos dados pessoais dentro da cooperativa, também é responsável por aceitar reclamações e comunicações dos titulares, receber comunicações da autoridade nacional e adotar providencias, orientar funcionários e contratados a respeito das práticas a serem adotadas em relação à proteção de dados e executar as demais funções atribuídas pelo controlador ${ }^{21}$. Dentre outras funções relevantes do Encarregado está a coordenação da elaboração do Relatório de Impacto, entre outros documentos relativos à proteção de dados pessoais e sensíveis em tratamento.

20 Lei ${ }^{\circ}{ }^{\circ}$ 5.764, de 16 de dezembro de 1971.

21 Lei 13.709/19, Art. 41, §2. ${ }^{\circ}$ 
Para que o tratamento dos dados pessoais esteja em conformidade e o Encarregado possa exercer sua função de modo adequado e satisfatório, muito se requisitará do Controlador. A segurança nesta nova modalidade, mais do que nunca, demanda dele a adoção das melhores e mais eficazes práticas no que se refere a proteção dos dados pessoais. $\mathrm{O}$ acesso deve ser restrito e segmentado na forma da necessidade, evitando assim o uso indevido ou não autorizado, como também os incidentes, a destruição acidental ou ilícita, a perda, alteração, comunicação ou difusão dos dados pessoais²2.

Sob essa perspectiva, a privacidade e a proteção de dados ganham protagonismo no cenário atual e requerem o entrelaçamento das práticas de segurança da informação, conformidade legal e de gestão de processos. O processamento e fluxo de dados passam a exigir procedimentos que levem em consideração a privacidade dos dados pessoais dos titulares em sentido amplo. O rastreamento dos dados nos bancos de dados, ciência sobre a finalidade a que se destina, o tempo de permanência destes na base e informações sobre eventuais compartiIhamentos, passarão a fazer parte do cotidiano dos agentes de tratamento de dados e isso inclui as cooperativas.

Para maior efetividade, uma nova rotina deve ser criada e os antigos procedimentos revisados de acordo com as bases legais previstas no art. 7. ${ }^{\circ}$ da Lei 13.709/18. A Lei prevê dez bases legais que vão desde o consentimento do titular ao legítimo interesse do controlador ou de terceiros, passando pelo exercício regular do contrato. Para cada ato, seu propósito deve ser identificado e articulado com a base legal que respalde o seu tratamento, ponderados os princípios norteadores da LGPD.

Desta forma, inconteste que estamos diante de uma nova realidade com desafios diários e mudanças significativas e relevantes. A gestão democrática das cooperativas acompanha esse processo evolutivo e as cooperativas precisam investir em tecnologia e recursos para manter as suas obrigações em dia e, ao mesmo tempo, garantir aos titulares a proteção dos dados adequados. A Assembleia digital ou semipresencial é uma ótima solução, desde que assegure a idoneidade dos atos praticados nesta. O acesso e a participação direta dos cooperados será cada vez mais exigido e a segurança não pode estar à margem desse processo. Esse é um caminho sem volta. 


\section{4. À guisa de conclusão: o paradoxo da liberdade coercitiva}

Poder-se-á dizer que as grandes guerras do sec. xx (incluindo aí a guerra fria) foram cruentas convulsões na afirmação da democracia moderna, uma vez que nelas por fim prevaleceram nações efetivamente dirigidas por Estados Democráticos de Direito e constituintes de sociedades de mercado e colaborativas através de organismos públicos transnacionais. No entanto, também essas guerras de números massivos testemunharam que a objetividade do desempenho (concebida pela modernidade como meio de emancipação do ser humano) não resolve frenesis de morte que assaltam as civilizações de tempos em tempos com variadas intensidades e modos quase nunca previsíveis. Ao contrário, intensifica seus efeitos patológicos tanto quanto fascina com seus espetaculares artifícios de poder desejar. No humanismo contemporâneo que transita, forjam-se sujeitos autônomos como máquinas desejantes ou doentes neuronais. Os nem-um-nem-outro passam por debaixo do radar: Yes, we can... but I would prefer not to ${ }^{23}$.

23 «Padres do deserto» é uma expressão que designa um fenômeno ocorrido durante a dissolução da civilização romana cristianizada e aluvião das tribos pagãs. Há algum paralelo entre o que vivemos hoje e o que aconteceu há mais de um milênio e meio atrás. Para os cidadãos de então, como nós, havia sensações de insegurança quanto ao modo de vida conhecido, de incerteza sobre o porvir e de crise cultural que predominavam sobre as de estabilidade, de continuidade e de coesão sociais. Esses «padres do deserto» deram expressividade a essas sensações convulsivas como nenhum outro modo de pensar foi capaz até hoje. Esta expressividade nos foi legada através dos apotegmas, que são pequenas estórias nas quais uma frase atribuída a um padre do deserto lhe dá sentido. Historicamente, esses "padres do deserto», pelo exemplo de vida e ensinamento, criaram o modelo das regras monásticas, tão importantes que foram para a preservação da memória civilizatória ao longo dos séculos de diluição proporcionada pelas chamadas «invasões bárbaras» às então correntes relações sociais citadinas; choques culturais em tempos de intensos fluxos migratórios num mundo conhecido como tal. Aliás, nenhuma imagem talvez capte tão bem estabilidade do que a de um mosteiro milenar encarapitado no alto de um penhasco. A linguagem usual sobre empatia hoje em dia parece ser tributária de uma ideia de "salto para cima». Que haja um estado culminante de ser si-mesmo a ser aspirado com o propósito de realização de um sonho. Não faltam apotegmas que coloquem em xeque a sinceridade e a autenticidade de propósitos moralizantes apresentados como metas voltadas à própria reputação. Os "padres do deserto», quando falam de estabilidade, não dizem que ela esteja numa aspiração bem intencionada de algo proposto para além. Mas, em autossuportar, num sentido muito mais psicanalítico (cuidado de si) do que de desempenho performático: «Filho, se queres ter proveito, permanece em teu próprio claustro, presta atenção em ti mesmo e em teu trabalho manual. Pois, ao sair por aí não teria o mesmo progresso profícuo que no silêncio presente de seu lar.» Apotegma 878. Apophthegmata Patrum Aegyptiorum. Em The Sayings of the Desert Fathers. Trad. Benedicta Ward. (Kalamazoo: Cistercian Publications, 1975), 227. 
As sociedades democráticas de mercado se mostraram hábeis e se lançaram à aceleração tecnológica em geração exponencial de dados, um dos sintomas mais evidentes da febre performático-produtiva que Ihes é rebento, e com isso trouxeram consigo um perigo que hoje thes testa a resiliência: a normatividade inflacionária de marcos regulatórios. Quanto mais o sujeito de direito for livre de qualquer heteronomia, maior o volume de normas positivadas que regulam essa liberdade. Eis o paradoxo da liberdade coercitiva em expansão. As cooperativas vivenciam intensamente essa tensão instável entre a supremacia democrática manifesta em suas assembleias e o desempenho tecnológico marcado por uma densa normatividade regulatória. É esta a questão de fundo posta na correlação entre as Leis 13.709/18 e 14.030/20, que foram abordadas neste artigo.

\section{Apêndice}

Instrução Normativa n. ${ }^{\circ} 81 / 2020$

do Departamento Nacional de Registro Empresarial e Integração

Anexo $\mathrm{VI}$ '- Manual de registro de cooperativa

Seção III - Das reuniões e assembleias semipresenciais ou digitais

Esta seção regulamenta a participação e a votação a distância em reuniões e assembleias de cooperativas.

Exclusivamente, para os fins do disposto nesta seção, as reuniões e assembleias podem ser:

I. semipresenciais - quando os associados puderem participar e votar presencialmente, no local físico da realização do conclave, mas também a distância, nos termos do item 1; ou

II. digitais - quando os associados só puderem participar e votar a distância, nos termos do item 1, caso em que o conclave não será realizado em nenhum local físico.

Nota: Esta seção não se aplica às reuniões e assembleias em que a participação e a votação de associados sejam exclusivamente presenciais. 


\subsection{Formas de participação e votação a distância}

A participação e a votação a distância dos associados podem ocorrer mediante o envio de boletim de voto a distância e/ou mediante atuação remota, via sistema eletrônico.

Para todos os fins legais, as reuniões e assembleias digitais serão consideradas como realizadas na sede da sociedade.

\subsection{Formalidades prévias ao conclave}

I. As reuniões e assembleias semipresenciais ou digitais deverão obedecer às normas atinentes à cooperativa, bem como às normas do estatuto social, quanto à convocação, instalação e deliberação.

II. Os documentos e informações a serem disponibilizados previamente à realização da reunião ou assembleia semipresencial ou digital devem não apenas observar os mecanismos de divulgação já previstos em lei, como também ser disponibilizados por meio digital seguro.

III. O instrumento de convocação deve informar, em destaque, que a reunião ou assembleia será semipresencial ou digital, conforme o caso, detalhando como os associados podem participar e votar a distância.

IV. As informações de que trata o inciso III deste item poderão ser divulgadas no anúncio de convocação de forma resumida, com indicação de endereço eletrônico na rede mundial de computadores onde as informações completas devem estar disponíveis de forma segura.

V. A sociedade deve adotar sistema e tecnologia acessíveis para que todos os associados participem e votem a distância na assembleia ou reunião semipresencial ou digital.

VI. O anúncio de convocação deve listar os documentos exigidos para que os associados, bem como seus eventuais representantes legais, sejam admitidos à reunião ou assembleia semipresencial ou digital.

VII. A sociedade pode solicitar o envio prévio dos documentos mencionados no anúncio de convocação, devendo ser admitido o protocolo por meio eletrônico.

VIII. O associado pode participar da assembleia ou reunião semipresencial ou digital desde que apresente os documentos até trinta minutos antes do horário estipulado para a abertura dos trabalhos, ainda que tenha deixado de enviá-los previamente. 
NOTAS

a) A sociedade não poderá ser responsabilizada por problemas decorrentes dos equipamentos de informática ou da conexão à rede mundial de computadores dos associados, assim como por quaisquer outras situações que não estejam sob o seu controle.

b) A sociedade pode contratar terceiros para administrar, em seu nome, o processamento das informações nas reuniões ou assembleias semipresenciais e digitais, mas permanece responsável pelo cumprimento do disposto nesta seção.

c) A sociedade deverá manter arquivados todos os documentos relativos à reunião ou assembleia semipresencial ou digital, bem como a gravação integral dela, pelo prazo aplicável à ação que vise a anulá-la.

\subsection{Critérios para aferição da presença}

Para todos os efeitos legais, considera-se presente na reunião ou assembleia semipresencial ou digital, conforme o caso o associado:

I. Que a ela compareça ou que nela se faça representar fisicamente;

II. cujo boletim de voto a distância tenha sido considerado válido pela sociedade; ou

III Que, pessoalmente ou por meio de representante, registre sua presença no sistema eletrônico de participação e voto a distância disponibilizado pela sociedade.

\subsection{Da participação a distância}

\subsubsection{DA UTILIZAÇÃO DE SISTEMA ELETRÔNICO}

O sistema eletrônico adotado pela sociedade para realização da reunião ou assembleia semipresencial ou digital deve garantir:

I. A segurança, a confiabilidade e a transparência do conclave;

II. O registro de presença dos associados;

III. A preservação do direito de participação a distância do associado durante todo o conclave;

IV. O exercício do direito de voto a distância por parte do associado, bem como o seu respectivo registro; 
V. A possibilidade de visualização de documentos apresentados durante o conclave;

VI. A possibilidade de a mesa receber manifestações escritas dos associados;

VII. A gravação integral do conclave, que ficará arquivada na sede da sociedade; e

VIII. A participação de administradores, pessoas autorizadas a participar do conclave e pessoas cuja participação seja obrigatória.

Nota: Nas cooperativas, o sistema de que trata este item deve garantir também anonimização dos votantes nas matérias em que o estatuto social previr o voto secreto.

\subsection{Do boletim de voto a distância}

\subsubsection{REQUISITOS EXIGIDOS}

O boletim de voto a distância deve conter:

I. Todas as matérias constantes da ordem do dia da reunião ou assembleia semipresencial ou digital a que se refere;

II. Orientações sobre o seu envio à sociedade;

III. Indicação dos documentos que devem acompanhá-lo para verificação da identidade do associado, bem como de eventual representante; e

IV. Orientações sobre as formalidades necessárias para que o voto seja considerado válido.

Nota: A sociedade deve disponibilizar o boletim de voto a distância em versão passível de impressão e preenchimento manual, por meio de sistema eletrônico disponível na rede mundial de computadores.

\subsubsection{CONTEÚDO}

A descrição das matérias a serem deliberadas no boletim de voto a distância:

I. Deve ser feita em linguagem clara, objetiva e que não induza o associado a erro;

II. Deve ser formulada como uma proposta e indicar o seu autor, de modo que o sócio precise somente aprová-la, rejeitá-la ou abster-se; e 
III. Pode conter indicações de páginas na rede mundial de computadores nas quais as propostas estejam descritas de maneira mais detalhada ou que contenham os documentos exigidos por lei ou por esta seção.

\subsubsection{Procedimento de enVIO e ReCEPÇÃo}

I. O boletim de voto a distância deve ser enviado ao associado na data da publicação da primeira convocação para a reunião ou assembleia semipresencial ou digital a que se refere, e deve ser devolvido à sociedade no mínimo cinco dias antes da data da realização do conclave.

II. A sociedade, em até dois dias do recebimento do boletim de voto a distância, deve comunicar:

a) O recebimento do boletim de voto a distância, bem como que o boletim e eventuais documentos que o acompanham são suficientes para que o voto do associado seja considerado válido; ou

b) A necessidade de retificação ou reenvio do boletim de voto a distância ou dos documentos que o acompanham, descrevendo os procedimentos e prazos necessários à regularização.

III. O associado pode retificar ou reenviar o boletim de voto a distância ou os documentos que o acompanham, observado o prazo previsto no inciso I deste subitem.

IV. O envio de boletim de voto a distância não impede o associado de se fazer presente à reunião ou assembleia semipresencial ou digital respectiva e exercer seu direito de participação e votação durante o conclave, caso em que o boletim enviado será desconsiderado.

\subsection{Assinaturas da ata e dos livros}

Os livros societários aplicáveis e a ata da respectiva reunião ou assembleia semipresencial ou digital poderão ser assinados isoladamente pelo presidente e secretário da mesa, que certificarão em tais documentos os associados presentes.

\subsection{Arquivamento da ata}

Para fins de registro, a cópia ou certidão da ata da reunião ou assembleia semipresencial ou digital deverá preencher os mesmos requi- 
sitos legais constantes deste Manual, naquilo que não conflitarem com essa seção.

\section{NOTAS}

I. Na ata da reunião ou assembleia deve constar a informação de que ela foi semipresencial ou digital, informando-se a forma pela qual foram permitidos a participação e a votação a distância, conforme o caso.

II. Os membros da mesa da reunião ou assembleia semipresencial ou digital deverão assinar a ata respectiva e consolidar, em documento único, a lista de presença.

III. Quando a ata do conclave não for elaborada em documento físico:

a) as assinaturas dos membros da mesa deverão ser feitas com certificado digital emitido por entidade credenciada pela Infraestrutura de Chaves Públicas Brasileira - ICP-Brasil ou qualquer outro meio de comprovação da autoria e integridade de documentos em forma eletrônica;

b) devem ser assegurados meios para que possa ser impressa em papel, de forma legível e a qualquer momento, por quaisquer associados; e

c) o presidente ou secretário deve declarar expressamente que atendeu todos os requisitos para a sua realização, especialmente os previstos nesta seção.

IV. Aplicam-se às reuniões e assembleias semipresenciais e digitais, subsidiariamente e no que com elas forem compatíveis, as disposições legais e regulamentares relativas às reuniões e assembleias exclusivamente presenciais.

$\mathrm{V}$. As reuniões ou assembleias presenciais já convocadas e ainda não realizadas, em virtude das restrições decorrentes da pandemia do Coronavírus (Covid-19), poderão ser realizadas de forma semipresencial ou digital, desde que todos os associados se façam presentes, nos termos do item 3 desta seção, ou declarem expressamente sua concordância.

\section{Referências bibliográficas}

Apophthegmata Patrum Aegyptiorum. 1975. Em The Sayings of the Desert Fathers. Trad. Benedicta Ward. Kalamazoo: Cistercian Publications. 
BIONI, Bruno Ricardo. 2019. Proteção de dados pessoais: a função e os limites

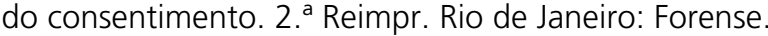

Han, Byung-Chul. 2015. Sociedade do Cansaço. Trad. Enio Paulo Giachini. Petrópolis: Vozes.

Tocqueville, Alex de. 2005 A Democracia na América. Leis e Costumes. Trad. Eduardo Brandão. 2. ${ }^{a}$ Ed. São Paulo: Martins Fontes. 


\section{Derechos de autor}

http://dec.revistas.deusto.es/

La revista Deusto Estudios Cooperativos es una revista de acceso abierto lo que significa que es de libre acceso en su integridad inmediatamente después de la publicación de cada número. Se permite su lectura, la búsqueda, descarga, distribución y reutilización legal en cualquier tipo de soporte sólo para fines no comerciales y según lo previsto por la ley; sin la previa autorización de la Editorial (Universidad de Deusto) o el autor, siempre que la obra original sea debidamente citada (número, año, páginas y DOI si procede) y cualquier cambio en el original esté claramente indicado.

\section{Copyright}

The Deusto Journal of Cooperative Studies is an Open Access journal which means that it is free for full and immediate access, reading, search, download, distribution, and lawful reuse in any medium only for non-commercial purposes, without prior permission from the Publisher or the author; provided the original work is properly cited and any changes to the original are clearly indicated. 